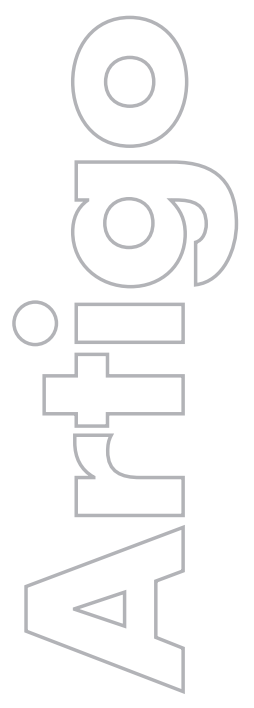

\title{
Áreas sociais - uma avaliação e perspectivas
}

\author{
Roberto Lobato Corrêa \\ PPGG-UFRJ; Nepec-UERJ
}

p. $10-33$

\section{revista}

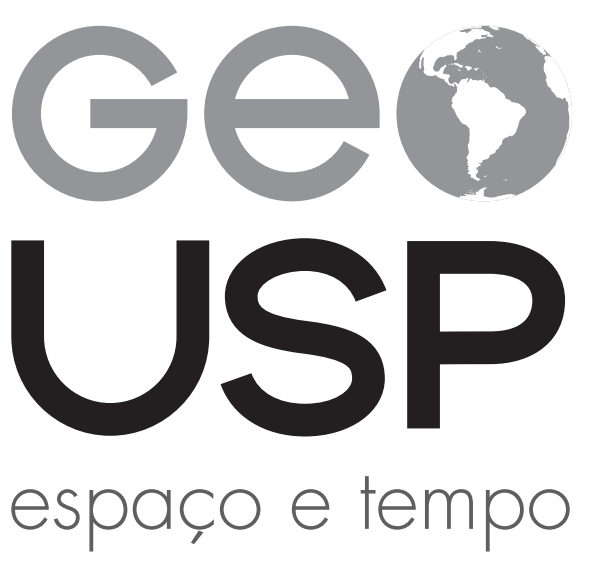

Volume $20 \bullet n^{\circ} 1(2016)$
Como citar:

CORREAA, R. L. Áreas sociais: uma avaliação e perspectivas. Geousp - Espaço e Tempo (Online), v. 20, n. 1, p. 10-33, mês. 2016. ISSN 2179-0892.

Disponível em: http://www.revistas.usp.br/geousp/article/ view/111752. DOI: http://dx.doi.org/10.11606/issn.2179-0892. geousp.2016.111752.

\section{(C) $(1) \Theta$}

Este artigo está licenciado sob a Creative Commons Attribution 4.0 License. 


\title{
Áreas sociais - uma avaliação e perspectivas $^{1}$
}

\section{Resumo}

Este texto considera o espaço social segundo as proposições da "análise de áreas sociais", resgatando criticamente uma abordagem de estudos urbanos que, entre 1950 e 1975, foi essencial para a geografia e a sociologia norte-americanas. Para tanto, parte-se da identificação de áreas relativamente uniformes no espaço urbano, centradas em aspectos sociais interligados tanto no plano conceitual como operacional. Duas partes essenciais orientam este trabalho: na primeira, realizou-se uma avaliação teórica dos estudos de áreas sociais, de sentido ecológico; na segunda, desenvolveram-se algumas perspectivas visando o uso dessa abordagem para o estudo do espaço das cidades brasileiras.

Palavras-chave: Áreas sociais. Ecologia humana. Espaço urbano. Tipologias. Segregação.

\section{Social areas: an evaluation and perspectives}

\begin{abstract}
This article considers the social space according to the propositions of the "social areas analysis", critically revisiting an approach to urban studies that, between 1950 and 1975, had great importance for Urban Geography and Sociology of the United States. It begins with the identification of relatively uniform areas in urban space, focusing on interrelated social aspects, both on conceptual and operational levels. Two essential parts guide this work: first, a theoretical assessment is carried out of social areas studies, in its ecological sense; second, some perspectives on the application of this approach to the study of Brazilian cities are developed.
\end{abstract}

Keywords: Social areas. Human ecology. Urban space. Typologies. Segregation.

1 Pesquisa patrocinada pelo Conselho Nacional de Desenvolvimento Científico e Tecnológico - CNPq. 


\section{Introdução}

○ espaço social pode ser analisado segundo várias abordagens distintas entre si, no que diz respeito à matriz teórica adotada e aos indicadores dela derivados. Este texto considera o espaço social segundo as proposições da "análise de áreas sociais". A adoção dessa abordagem deriva das possibilidades que oferece na identificação de áreas relativamente uniformes no espaço urbano, centradas em aspectos sociais interligados tanto no plano conceitual como operacional. A análise de áreas sociais permite, por outro lado, identificar diferentes tipos de cidades a partir de suas configurações espaciais.

A abordagem em questão gera um quadro classificatório, não tendo nenhum poder explicativo ou preditivo. Descreve, em realidade, os resultados diferenciados de complexos processos sociais. Expressos espacialmente, tais resultados podem se constituir em ponto de partida para novas investigações.

presente texto procura, em realidade, resgatar criticamente uma abordagem de estudos urbanos que, entre 1950 e 1975, teve enorme importância nas ciências que tratam do urbano. $\bigcirc$ resgate dessa abordagem tem por base a contínua necessidade de se pensar o espaço da cidade e a crença de que, a despeito das críticas efetivadas, o potencial de análise de áreas sociais para a compreensão do espaço urbano está longe de ter sido esgotado.

$\bigcirc$ presente texto divide-se em duas partes essenciais. Na primeira, faz-se uma avaliação sobre os estudos de áreas sociais; na segunda, apontam-se algumas perspectivas visando o uso dessa abordagem no estudo do espaço das cidades brasileiras.

\section{Áreas sociais: uma avaliação}

Esta seção procura avaliar os estudos sobre áreas sociais da cidade, estudos que tiveram grande importância no âmbito da sociologia e geografia urbanas. A avaliação não se constitui em objetivo, mas em meio que deverá permitir dar continuidade aos esforços visando obter inteligibilidade a respeito das relações entre sociedade, espaço e tempo.

A avaliação inicia-se com o resgate dos antecedentes do conceito de áreas sociais, seguindo-se a formulação teórica e a sua operacionalização. A sistematização dos resultados de estudos selecionados, seguido das críticas e novas proposições constituem, respectivamente, a terceira e quarta parte desta primeira seção.

\section{Os antecedentes: o conceito de áreas naturais}

$\bigcirc$ conceito de área natural constitui-se no antecedente do conceito de áreas sociais. Formulado por Robert Ezra Park em 1916 (Park, 1967), tornou-se um conceito-chave da Escola de Ecologia Humana ou Escola de Chicago, criada por Park na Universidade de Chicago na década de 1910. Segundo Entrikin (1980) o conceito de áreas naturais tem uma de suas bases no pensamento de Georg Simmel, com quem Park estudou em Berlim, entre 1899 e 1903. Simmel considerava o espaço social como importante condição para as formas sociais.

Park também incorporou a importância do espaço geográfico, apreendida em Strasbourg com Georg Gerland, e em Heidelberg, com Alfred Hettner (Entrikin, 1980). 
Presente no pensamento de Park, o conceito de áreas naturais foi sistematizado por Harvey Zorbaugh em 1926 (Zorbaugh, 1970), estando calcado na concepção que Park tinha sobre a cidade (Park, 1967, 1970). Segundo este autor, a cidade constitui-se em uma forma particular de comunidade, na qual a luta pela sobrevivência, ainda que sublimada, gera a competição impessoal entre indivíduos. Desse processo emergem grupos sociais, alguns dos quais dominantes, ao mesmo tempo em que é estabelecida a diferenciação natural de áreas, gerando áreas naturais, o "habitat dos grupos naturais" (Park, 1970, p. 135). As áreas naturais descrevem a configuração espacial e exprimem a ordem moral da cidade. Adicionalmente, as áreas naturais "impõem-se aos homens, formando-os, de acordo com o projeto e os interesses (nelas) incorporadas" (Park, 1967, p. 32). Assim, para Park, as áreas naturais ao incorporarem, por intermédios das formas e fluxos, o projeto e os interesses dos homens, participam ativamente do processo de reprodução de grupos sociais distintos entre si. A seu modo, apoiado em concepções calcadas em matrizes não críticas, Park antecipa-se ao pensamento, vigente após 1970, sobre o espaço urbano como lócus da reprodução das relações sociais, conforme apontado por Lefébvre (1976).

As áreas naturais resultam da localização e segregação no espaço urbano dos diversos grupos sociais, as quais são fortemente influenciadas pela capacidade que cada grupo tem em pagar para se localizar em uma área urbana já retalhada pela natureza, pela presença de vias de tráfego, indústrias, parques, atividades em geral e pela própria estrutura socioespacial preexistente.

A homogeneidade dos grupos sociais que caracteriza cada área natural traduz-se em "instituições, costumes, crenças, configurações da vida, tradições, atitudes, sentimentos e interesses" comuns (Zorbaugh, 1970, p. 343), que conferem às áreas naturais o caráter de áreas culturais. Nesse sentido, Park e seus discípulos admitiam, ainda que implicitamente, na década de 1920 e para as sociedades industriais, que o conceito de cultura incorporasse diferenças de ocupação, escolaridade e renda e não apenas aquelas associadas à raça, à etnia, à língua e à religião. Desse modo, antecipam-se às formulações de Raymond Williams feitas em 1958 sobre a natureza social e política de cultura (Williams, 1997).

Zorbaugh, por outro lado, enfatiza ainda a correspondência entre as características físicas, expressas na paisagem, existentes nas áreas naturais. A área natural é, assim, uma "área geográfica caracterizada tanto por uma individualidade física como pelas características do povo que nele vive" (Zorbaugh, 1970, p. 343).

Expressão de uma visão analógica à ecologia vegetal, as áreas naturais, como conceito, trazem com elas a perspectiva do darwinismo social que impregnou muito as ciências sociais do final do século XIX e início do século XX. As áreas naturais, adicionalmente, foram consideradas como entidades com existência concreta, como aparece nas palavras de Palmer e Burgess ao se referirem às 75 áreas naturais por eles identificadas em Chicago entre 1924 e 1930, conforme reproduzido em Bulmer (1984, p. 119). Segundo eles cada área natural era:

Uma sociedade em miniatura, com sua própria história e tradições, seus problemas específicos e sua própria concepção de futuro. Hyde Park [...] South Chicago [...] não são apenas nomes no mapa. Representam distintas unidades dentro da cidade, cada uma sendo, com certeza, uma parte dela, mas também apresentando seu papel específico no futuro de Chicago. 
Entidades concretas, partes integradas à cidade e condicionantes do futuro, as áreas naturais desempenharam importante papel na esfera do planejamento urbano. Estavam elas integradas à visão preditiva atribuída à Ecologia Humana, visão que derivava da perspectiva nomotética que Park absorvera de Wilhelm Windelband, seu orientador em Strasbourg e Heidelberg. Windelband estabelecera a distinção entre ciências nomotéticas, voltadas para a descoberta de regularidades empíricas, leis e capacidade preditiva, e ciências idiográficas, interessadas no estudo de situações únicas, que não se repetem (Entrikin, 1980; Capel, 1981).

O pragmatismo, em realidade, constituía-se em parte fundamental do pensamento de Park e de seus discípulos. Park fora aluno de William James e John Dewey, os teóricos do pragmatismo, uma filosofia que associa o real conhecimento a sua aplicabilidade (Entrikin, 1980; Jackson; Smith, 1984). O conceito de área natural foi, em realidade, visto como útil e necessário ao planejamento urbano, campo em que a Escola de Ecologia Humana estava fortemente engajada, como se exemplifica com a ativa participação de seus membros no Local Community Research Committee, criado em 1923 na Universidade de Chicago, cujas pesquisas voltavam-se ao planejamento urbano (Bulmer, 1984).

Tendo em vista o sentido pragmático conferido às áreas naturais, foram propostos indicadores, bases territoriais e um conjunto de procedimentos que operacionalizavam o conceito de áreas naturais. Por sua vez, essas proposições conferem à Escola de Ecologia Humana, o caráter de pioneira na investigação a respeito do espaço urbano, pioneirismo que data da década de 1920. Particular referência é devida a Ernest Burgess, cujo papel vai muito além de seu clássico e polemizado modelo de uso da terra urbana.

O conceito de área natural foi objeto de inúmeras críticas. As mais importantes dizem respeito ao atribuído caráter natural das áreas naturais, associado à pretensa ordem natural do "laissez-faire" capitalista, no qual grupos sociais distintos, com rendimentos diferenciados, competem pela terra urbana. As áreas naturais resultantes dessa competição refletem a desigualdade social, ambas vistas como sendo impossíveis de serem abolidas por resultarem de processos naturais: apenas podem ser desfeitas para serem refeitas logo após, restabelecendo-se o equilibrio fundado na desigualdade socioespacial (Jackson; Smith, 1984).

A divisão social do espaço, contudo, como outras espacialidades, é independente das interpretações que dela se pode fazer. A sua continuidade suscitaria a manutenção do interesse em torná-la inteligível. Nesse sentido, o conceito de áreas naturais irá ser substituído pelo de áreas sociais, um conceito mais elaborado e liberado da visão darwinista da cidade.

\section{Áreas sociais: a formulação teórica e sua operacionalização}

No estudo sobre as áreas sociais de Los Angeles, publicado em 1949 e considerado como o ponto de ruptura com a perspectiva focalizada no conceito de áreas naturais, Shevky e Williams (1949) propõem um modelo que define áreas socialmente homogêneas de Los Angeles, distinguindo semelhanças e diferenças socioespaciais (Shevky e Bell, 1974). Trata-se de uma tipologia de áreas intraurbanas baseada em três índices ou fatores, posição social (situação econômica), urbanização (situação familiar) e segregação. Cada unidade de área da cidade, isto é, cada setor censitário, é classificado de acordo com cada um desses índices. Aqueles setores semelhantes nos três índices constitui uma área social, resultante de uma classificação tridimensional (Shevky e Bell, 1974). 
Em 1955, a partir do estudo de Bell (1974) sobre as áreas sociais de San Francisco, a teoria das áreas sociais é formalizada por Shevky e Bell (1974). Para eles, a cidade é o resultado do caráter complexo, global e dinâmico da sociedade moderna. Então, trata-se de se relacionar a forma da cidade às características da sociedade que nela vive, privilegiando-se os processos de mudança da sociedade. Por sua vez, essas mudanças associam-se à escala da sociedade (societal scale), isto é, o número de pessoas se relacionando e a intensidade desse relacionamento. $\bigcirc$ aumento da escala (increasing scale) implica no aparecimento da sociedade urbano-industrial, associada às mudanças na estrutura das atividades produtivas, as quais afetam a organização socioespacial da cidade, complexificando-a. Segundo Shevky e Bell (1974), os três índices descrevem a complexidade do espaço social da cidade. Por intermédio deles pode-se realizar estudos a respeito de uma única cidade em um dado momento e estudos comparativos, envolvendo sincronicamente duas ou mais cidades ou, de modo diacrônico, uma mesma cidade. Um breve enunciado de cada índice é apresentado a seguir, extraído de Shevky e Bell (1974, p. 380-381).

i - Posição social - A construção deste índice deriva da diferenciação de indivíduos e grupos sociais na sociedade moderna, diferenciação que pode ser descrita pelos indicadores de ocupação, educação e preço da habitação. A ocupação é considerada como o mais importante indicador.

ii - Urbanização - Este índice deriva da estrutura mutável da atividade produtiva, sendo composto pelos indicadores fecundidade, mulheres ativas e unidades residenciais unifamiliares, que associam-se às mudanças do papel da mulher na sociedade moderna.

iii - Segregação - Este índice refere-se à tendência a concentração espacial de grupos étnicos diferentes, refletindo também o processo de complexificação da sociedade moderna, que inclui a migração. $\bigcirc$ indicador que descreve este índice é grupos raciais e nacionais.

Os três índices são objetivados, cada um, por um grande número de variáveis, originalmente e respectivamente, nove, quatro e três variáveis. Na prática, no entanto, as variáveis foram parcialmente modificadas e, via de regra, o número delas foi ampliado, refletindo interpretações distintas a respeito dos indicadores, as dificuldades de acesso às informações, ou ainda a possibilidade, graças às técnicas multivariadas, de explorar novos caminhos.

A partir da aplicação de procedimentos mais sofisticados, a análise fatorial e a análise de agrupamento (Bell, 1974), a teoria das áreas sociais foi objeto de grande interesse. Subjacente estavam velhas questões levantadas pela Ecologia Humana e novas questões que a realidade social demandava em consequência da expansão urbana no pós-guerra. $\bigcirc$ planejamento urbano, em voga, constituía-se em outro impulso para os estudos sobre áreas sociais.

A adoção da análise fatorial foi tão significativa que os estudos de áreas sociais foram, crescentemente, denominados estudos de ecologia fatorial, enquanto os três índices de Shevky e Bell (1974) de fatores.

A análise fatorial constitui uma estatística multivariada de natureza descritiva. $\bigcirc$ ponto de partida é uma matriz de informações na qual nas linhas estão as unidades observacionais, setores censitários no caso dos estudos sobre áreas sociais, e nas colunas informações expressas em variáveis, no caso relativas aos indicadores associados aos índices de posição social, urbanização e segregação. A análise fatorial reduz o número de variáveis, via de regra elevado, a um reduzido número de fatores, cada um constituído por um grupo de variáveis altamente cor- 
relacionadas entre si. Os fatores são independentes entre si, isto é, as variáveis que compõem cada fator não estão correlacionadas entre si ou estão fracamente correlacionadas. Os fatores, por outro lado, estão hierarquizados, cada um apresentando um peso diferente, expresso em percentagem, na "explicação" da variação das características de diferenciação social relativa ao conjunto de variáveis em um dado número de unidades observacionais. A independência dos fatores e o peso relativo de cada um constituem elementos-chave para se verificar a teoria das áreas sociais, calcada em três índices ou fatores, posição social, urbanização e segregação.

A análise fatorial, por outro lado ainda, produz também uma classificação de cada unidade de área em relação a cada fator. Trata-se do factor score, que indica quantitativamente a importância de cada unidade de área no âmbito de cada fator. Por intermédio da análise de agrupamento é possível agrupar os setores censitários que apresentam as mesmas combinações de fatores obtidos da análise fatorial. Sugere-se que, para maiores esclarecimentos sobre a análise fatorial e de agrupamento, consulte-se, entre outros, Berry (1971), Rees (1971) e Johnston (1971).

mapeamento dos factor scores possibilita evidenciar o padrão espacial do fator, ou seja, em princípio, da posição social, urbanização e segregação. Obtêm-se, assim, três mapas parciais sobre o espaço social da cidade. $\bigcirc$ mapeamento dos grupos de setores censitários, derivados da análise de agrupamento, por outro lado, desenha as áreas sociais da cidade.

A configuração espacial das proposições de Shevky e Bell (1974) foram apresentadas por Anderson e Egeland (1974) em 1961. Combinaram eles os modelos clássicos de Burgess, em zonas concêntricas, de Hoyt (1958), em setores, e de Harris e Ullman, em múltiplos núcleos, com os três índices de Shevky e Bell (1974), respectivamente, urbanização, posição social e segregação. Três espacialidades distintas emergem, evidenciando a relativa independência dos três índices ou fatores propostos por Shevky e Bell (1974). A combinação das três espacialidades, proposta por Murdie (1969) em seu estudo sobre a ecologia fatorial da cidade canadense de Toronto, gera um modelo espacial agregado complexo.

\section{Áreas sociais: concordâncias e discordâncias}

Entre 1950 e o final da década de 1970 sociólogos e geógrafos realizaram inúmeros estudos sobre áreas sociais em diversos contextos econômicos e culturais. A despeito de terem sido consideradas informações distintas em termos quantitativos, qualitativos, em relação às datas das informações e face às unidades observacionais, os estudos permitem uma avaliação dos resultados. Discordâncias e concordâncias em relação às formulações de Shevky e Bell (1974) podem ser apontadas, assim como os estudos indicam a necessidade de se repensar criticamente a respeito das relações entre processos e formas espaciais, particularmente considerando-se o Brasil.

Os seguintes pontos podem ser ressaltados a propósito das concordâncias e discordâncias, estas sendo aqui mais enfatizadas.

i - Os três fatores, posição social, urbanização e segregação emergiram nas análises fatoriais relativas às cidades norte-americanas. Exemplifica-se com os resultados do estudo de Van Arsdol Jr., Camilleri e Schmid (1974) sobre 10 cidades norte-americanas, com base em informações relativas a 1950. Pequenas discordâncias foram consideradas irrelevantes. 
ii - Em alguns estudos além dos três fatores sugeridos, um ou mais fatores adicionais emergiram, como no estudo de Helsinki realizado por Sweetser (1974) ou no estudo de Bailly e Polèse (1977) sobre as cidades canadenses de Edmonton e Quebec. Contudo, o afastamento às formulações de Shevky e Bell (1974) não levou os autores em tela a apontarem discordâncias efetivas.

iii - $\bigcirc$ peso relativo do fator posição social, considerado o maior na formulação de Shevky e Bell (1974), nem sempre foi constatado. Em Edmonton e Quebec o fator que descreve a urbanização emergiu com maior peso que o fator posição social.

iv - Estudos diacrônicos evidenciaram a não estabilidade da organização social da cidade. Exemplifica-se com o estudo de Schmid, MacCannell e Van Arsdol Jr. (1974) sobre 23 cidades norte-americanas e relativo aos anos de 1940 e 1950, no qual as mesmas variáveis foram consideradas. A despeito da manutenção da estabilidade do fator posição social, constatou-se, contudo, alterações relativas aos fatores urbanização e segregação, evidenciando mudanças sociais e espaciais.

$\mathrm{v}$ - A tese de independência entre os três fatores, central na proposição de Shevky e Bell (1974), não foi verificada em outros contextos socioculturais distintos do contexto dos países industriais, os Estados Unidos em particular. As variáveis que descrevem posição social, urbanização e segregação combinam-se de modos distintos, originando dois ou mais fatores e não três fatores independentes.

Esta discordância revela apenas a complexidade do mundo real e são estimulantes para o processo de compreensão de uma realidade na qual diferenças culturais e uma profunda desigualdade social são traços fundamentais. Dada a importância dessa discordância ela será privilegiada.

Em seu estudo sobre as áreas sociais da cidade do Cairo Abu-Lughod (1969) considerou informações relativas aos anos de 1947 e 1960. Foram 13 variáveis consideradas, relativas à estrutura demográfica, às características da família, ao nível socioeconômico e à composição étnica. $\bigcirc$ estudo considera 206 setores censitários.

Tendo em vista a teoria das áreas sociais, a contribuição mais importante deste estudo refere-se à associação entre variáveis que descrevem urbanização e posição social, que emergiram no mesmo fator. Esse resultado remete à noção de aumento da escala da sociedade, na qual em sociedades menos complexas posição social e urbanização são correlatos, isto é, classe social e família estão intrinsecamente ligados e não dissociados como nas sociedades mais complexas, gerando a independência entre os fatores posição social e urbanização.

Resultado semelhante foi obtido por Corrêa e Fredrich (inédito) em relação à cidade de San José, capital da Costa Rica. A partir de uma análise fatorial relativa ao ano de 1970, com 29 variáveis (16 relativas à posição social, 9 à urbanização, 2 ao crescimento demográfico e 2 ao uso da terra) e 42 unidades observacionais, verificou-se que as variáveis que descrevem a urbanização estão juntas com aquelas associadas à posição social. Esta associação se deu nos dois fatores denominados status socioeconômico 1 e status socioeconômico 2, distintos entre si porque no primeiro há oposição entre ricos e pobres, enquanto no segundo entre a classe média e os pobres.

Por outro lado, ao se mapear os factor scores, verificou-se também que a cidade de San 
José se caracteriza por um modelo pré-industrial de organização espacial, modelo no qual a população de alto nível de renda localiza-se próxima ao centro da cidade, enquanto os pobres, na periferia.

O estudo de Morris e Pyle (1971) sobre as áreas sociais da cidade do Rio de Janeiro, confirma também, em linhas gerais, os resultados discordantes obtidos para as cidades do Cairo e San José. No estudo sobre o Rio de Janeiro foram considerados 22 variáveis relativas ao ano de 1960 e quatro conjuntos de unidades observacionais: 74 bairros, incluindo as favelas; os mesmos 74 bairros sem as favelas; as favelas; e 121 unidades correspondendo aos 74 bairros e mais as favelas, consideradas como destacadas dos bairros. Para cada um dos quatro conjuntos foi realizada uma análise fatorial.

Os resultados obtidos para o primeiro, segundo e quarto conjunto guardam certa semelhança entre si, enquanto a análise para as favelas apresentou resultados distintos. Nas três análises fatoriais relativas aos bairros o fator mais importante foi o da posição social, mas no quarto conjunto considerado (bairros e favelas separados) esse ator continha variáveis que descreviam a urbanização, abrangendo 14 das 22 variáveis. $\bigcirc$ segundo fator em todas as três análises dizia respeito às migrações, enquanto os demais apresentaram sempre reduzida importância.

É significativo apontar que, a despeito do estudo de Morris e Pyle (1971) estar baseado em bairros e não em setores censitários e o de Corrêa e Fredrich em detritos, os resultados, contudo são consistentes entre si e aqueles relativos à cidade do Cairo, apontando discordância em relação às proposições de Shevky e Bell (1974): os três fatores não emergiram, verificando-se a fusão de variáveis associadas aos fatores posição social e urbanização, indicando assim, a não independência entre eles e sugerindo uma relativamente menor escala da sociedade.

\section{Áreas sociais: críticas e novas proposições}

Se os resultados concordantes e discordantes ampliaram o conhecimento sobre o espaço social da cidade, as críticas e novas proposições possibilitaram novos avanços. De fato, tanto o conceito de áreas sociais e a ecologia fatorial foram submetidos a inúmeras críticas. Vejamos as mais significativas.

i - As críticas de Hawley e Duncan (1957) dizem respeito, primeiramente, ao perigo de se propor que os fatores derivados de estatísticas com base em setores censitários sejam adequadas para os estudos sobre o espaço urbano porque não são capazes de identificar os fatores realmente cruciais de diferenciação e estratificação urbana. Em segundo lugar, as áreas sociais identificadas com base em setores censitários não são necessariamente homogêneas. $E$ em terceiro lugar, os estudos sobre áreas sociais não estão apoiados em uma teoria social que explique porque as áreas sociais tendem a ser homogêneas.

ii - A noção de aumento da escala da sociedade foi criticada por Udry (1964) e McElrath $^{2}$ (apud Timms, 1971). Assim, Udry (1964) argumenta que se os três fatores propostos por Shevky e Bell (1974) resultam da evolução da sociedade, que se torna mais complexa, é de se esperar que em uma análise diacrônica um determinado comportamento seja verificado ao se

2 McElrath, D. C. The social areas of Rome: a comparative analysis. American Sociological Review, v. 27, n. 3, p. 376-91, 1962. 
considerar o mesmo universo espacial e de variáveis. Ao verificar esta tese para os Estados Unidos, considerando sete variáveis condizentes com as formulações de Shevky e Bell (1974)e para vários anos entre 1850 e 1960, Udry (1964) constatou que, de um lado, algumas variáveis evoluíram consistentemente com o que se esperava: aumento da participação feminina na força de trabalho e do número de pessoas empregadas em escritórios e diminuição da população empregada nas atividades primárias. De outro, a diminuição da fertilidade foi constante até 1940, aumentando depois, indicando que aquela diminuição não se associa sempre ao aumento da complexidade social. De outro ainda, flutuaram as variáveis descrevendo mobilidade interestadual - percentagem de população ativa e prédios ocupados inicialmente com residências unifamiliares -, não se associando à ideia de aumento da escala da sociedade.

McElrath (1962), a partir de seu estudo sobre as áreas sociais de Roma, realizado em 1968, argumenta que a noção de escala da sociedade deve ser considerada de modo menos restritivo. Para ele a industrialização e a urbanização constituem as bases a partir das quais estrutura-se a sociedade e seu espaço. Segundo McElrath (1962), mudanças no processo de industrialização originam mudanças na distribuição de habilidades e na organização da sociedade, gerando dois eixos de diferenciação, status socioeconômico (posição social) e status familiar (urbanização). Mudanças na urbanização implica agregração de população e aumento na dispersão de recursos, inclusive humanos, originando dois outros eixos, status do migrante e status étnico.

iii - Os estudos sobre as áreas sociais das cidades do denominado Terceiro Mundo, especialmente o de Abu-Lughod (1969) não apenas apontaram a necessidade de revisão da tese da independência dos fatores, mas também alertaram para que se considerasse mais atentamente as mudanças ao longo do tempo e as características culturais de sociedades não ocidentais, assentadas em lógicas distintas daquelas da sociedade ocidental. De fato, a inexistência de modelos convincentes a respeito da estrutura social e de suas relações com o espaço urbano, gerou uma visão acrítica da sociedade e do espaço (Short, 1976).

iv - Do ponto de vista metodológico Udry (1964) aponta para os problemas de interpretação a partir da mudança da escala de observação, mantendo-se, no entanto, as mesmas variáveis. Assim, ao se considerar setores censitários, áreas metropolitanas e regiões, os resultados apresentarão diferenças. As proposições de Shevky e Bell (1974) podem ser úteis para estudos de áreas sociais a partir dos setores censitários: estudo para 89 áreas metropolitanas, consideradas cada uma de modo agregado, evidenciou resultados distintos daqueles propugnados por Shevky e Bell (1974).

Na mesma direção, mas enfatizando a epistemologia, é a crítica de Jackson e Smith (1984). Argumentam eles que na ecologia fatorial os pesquisadores aceitaram a tese positivista de que as regularidades empíricas em torno de correlações envolvendo variáveis e espaço garantam a imposição de relações causais e consequentemente a formulação de leis. Subjacente há a crença de que "a realidade está presente na aparência [... ] os objetos existem independentemente do observador [e] que podem ser mensurados repetidamente para formar a base de leis que podem ser verificadas recorrendo-se aos fatos empíricos" (Jackson; Smith, 1984, p. 7).

A partir das concordâncias, discordâncias e críticas, novas proposições foram elaboradas; entre elas, tipologias relativas às variações do espaço social da cidade. As tipologias respondem, em parte, às críticas formuladas, mas o que deve ser ressaltado é que constituem 
avanço considerável, estabelecendo conexões entre os diversos contextos econômicos e culturais e as formas de organização do espaço social. As tipologias dizem respeito a modelos particulares e não a um modelo universal de espaço social da cidade. Os tipos que constituem cada tipologia, por outro lado, não devem ser vistos como uma sequência, na qual seria possível passar de um tipo anterior a outro posterior, mais complexo. As linhas de evolução são múltiplas, não importando nenhuma visão etapista. Uma das razões para não se conceber a perspectiva etapista reside na força de inércia do espaço urbano, enquanto outra, mais importante, que impediria uma homogeneidade do espaço social das cidades, reside na necessária desigualdade socioespacial do capitalismo, como aponta Browett (1984).

No presente estudo considera-se a tipologia proposta por Timms (1971), construída com base em generalizações, deduções e em argumentos apresentados por McElrath (1962), que the possibilitou introduzir um quarto fator de diferenciação socioespacial, por ele denominado de migração. Sua tipologia contempla seis tipos de cidades, resultantes de distintas combinações entre os quatro fatores, envolvendo cidades de vários contextos socioculturais. Os seis tipos são:

- Cidade moderna, na qual os quatro fatores emergem independentes uns dos outros; esse tipo é o que mais se aproxima da proposição de Shevky e Bell (1974).

- Cidade feudal, que corresponde ao tipo oposto, no qual emerge um único fator, indicando uma única linha de variação do espaço social.

- Cidade colonial, que se caracteriza por dois fatores, um que reúne variáveis do fator status socioeconômico, grupo minoritário e migração, e outro, caracterizado pelas variáveis descrevendo o status familiar, como foi apontado por Sjoberg (1960).

- Cidade de imigrantes, que apresenta, de um lado, o fator status socioeconômico e, de outro, um fator que aglutina variáveis relativas ao status familiar, minoria e migração.

- Cidade pré-industrial, que apresenta uma nítida associação entre variáveis que descrevem o status socioeconômico e o status familiar, como foi sugerido por Sjoberg (1960); um segundo fator de diferenciação começa a emergir, agrupando variáveis ligadas ao fator minoria e migração.

- Cidade em industrialização, na qual começa a emergir uma separação entre os fatores status socioeconômico e status familiar, ao mesmo tempo que começa a emergir um terceiro fator que reúne variáveis relativas ao fator minoria e migração; a tese do aumento da escala da sociedade está presente neste, que antecipa o tipo cidade moderna.

Consideramos a proposição de Timms (1971) uma grande contribuição na direção da construção de uma teoria a respeito das relações entre sociedade e espaço urbano, que incluirá as possíveis variações, as particularidades socioespaciais. Sugerimos ser importante reter os tipos cidade moderna, cidade em industrialização, cidade de imigrantes e cidade pré-industrial, que parecem ser relevantes para a interpretação das cidades brasileiras.

\section{Áreas sociais: perspectivas}

A análise da literatura sobre áreas sociais impõe algumas questões que visam estabelecer novas perspectivas para esta temática, cuja importância deve-se ao fato de as áreas sociais, entendidas como formas espaciais derivadas de processos sociais, descreverem a divisão social 
do espaço, que reflete e condiciona a sociedade. Elaboração e reelaboração social, sintetiza um conjunto de valores, crenças e utopias expressos em intenções e práticas, nas quais estão presentes contradições e conflitos, mas também cooperação.

As críticas elaboradas à temática das áreas sociais não excluem a necessidade de prosseguir pensando criticamente a divisão social do espaço urbano. Esta seção procura contribuir nesta direção, considerando primeiramente a segregação residencial em uma perspectiva crítica, seguindo-se a discussão do conceito de práticas espaciais e, finalmente, considerando a cidade brasileira como objeto de interesse para estudos sobre áreas sociais.

\section{Segregação residencial: uma visão crítica}

A segregação residencial constitui um dos conceitos básicos da Escola de Ecologia Humana, elaborado a partir dos princípios de ecologia vegetal de competição, dominação, invasão e sucessão. Na formulação de Shevky e Bell (1974) a segregação foi associada à etnia, constituindo o terceiro fator da proposição formulada por eles. No presente trabalho a segregação é considerada como o aspecto essencial das áreas sociais, enquanto os aspectos étnicos são considerados como parte da segregação, sendo identificados como etnicidade. A essencialidade da segregação residencial na definição de áreas sociais é compartilhada, entre outros, por Harris (1984) e Udry (1964).

Segundo Harris (1984), a segregação residencial está intrinsecamente vinculada às classes sociais. Afirma Harris (1984, p. 26) que:

A segregação das classes sociais é um aspecto distintivo da cidade capitalista [...]. Historicamente [...] apareceu em sua forma atual somente com a separação entre lugar de trabalho e residência, criando as condições para o desenvolvimento de um específico mercado de habitação (que) se tornou o mecanismo pelo qual as relações de classe no novo sistema de produção (industrial) fossem refletidas no espaço residencial urbano.

Segundo Harris (1984), a segregação compreende a "segregação de classes" e a "diferenciação residencial", que devem ser consideradas juntas e não separadamente ou privilegiando-se a segunda em detrimento da primeira, como ocorreu nos estudos de áreas sociais. A segregação de classes refere-se ao fato das classes sociais "diferenciarem-se em termos de sua distribuição residencial" (Harris, 1984, p. 28), enquanto a segunda diz respeito à diferenciação de áreas em termos de sua composição social. No presente trabalho a segregação residencial é entendida como intrinsecamente vinculada às classes sociais em seus espaços de existência e reprodução, gerando áreas sociais nas quais há uma tendência a uma relativa homogeneidade interna e heterogeneidade entre elas (Castells, 1971).

As dificuldades para o estudo da segregação estão, em parte, vinculadas à escala e à definição de classes sociais. A segregação pode ser estudada em várias escalas, a partir de setores censitários, quarteirões, bairros e zonas da cidade: a mudança de escala implica em resultados diferentes, como já apontado por Udry (1964). O conceito de classes sociais, por sua vez, é problemático. De acordo com Harris (1984, p. 28), as classes sociais são "fenômenos históricos que emergem por meio de conflitos e antagonismos mútuos [...] diferem mais significativamente 
em termos de sua posição no processo produtivo", isto determinando a forma de consciência e a atividade política. As classes sociais têm tanto existência objetiva como subjetiva. Ao não se considerá-las nos estudos de segregação residencial, cria-se a lacuna, entre outras, relativa ao papel da segregação residencial no processo de formação de classes sociais, como aponta Harris (1984). Semelhantemente Katznelson (1992) discute o papel da segregação residencial no século XIX no processo de formação da classe operária, questão que tem como ponto de partida o seminal texto de Engels (1975), publicado em 1845 e referente à cidade de Manchester.

É nesse sentido que Harvey (1975) rejeita a ideia de que a diferenciação residencial seja devida ao fato de que indivíduos semelhantes quanto à renda e ao padrão cultural tendam a residirem juntos, daí resultando áreas residenciais internamente homogêneas e heterogêneas entre si. Como o próprio Harvey (1975) argumenta, não se sabe se os indivíduos são semelhantes porque residem próximo ou se residem próximo porque são semelhantes. Adicionalmente, Harvey (1975) rejeita também a ideia da economia neoclássica de que a diferenciação residencial resulte da soberania do consumidor, visto em sua independência de escolha face a um mercado considerado perfeitamente competitivo, e de seu comportamento, que tende a maximizar a utilidade das localizações, a qual dependeria do jogo entre densidade e tamanho da unidade domiciliar.

Harvey (1973) argumenta sobre a necessidade de se conhecer o processo de estruturação de classes sociais para que se possa avançar em uma teoria crítica sobre a segregação residencial. Considerando as contribuições de Marx, Giddens e Poulantzas, Harvey (1973) admite que na sociedade capitalista da metade do século XX, a estruturação de classes sociais e suas frações advêm da conjunção de três forças, primária, residual e derivativas. As forças primárias são aquelas que dividem a sociedade em duas classes sociais maiores, os proprietários dos meios de produção e aqueles que apenas têm a força de trabalho para vender. A esta polarização são acrescentados os resultados da ação das outras duas forças, que complexificam a sociedade. As forças residuais possibilitam a permanência de classes sociais herdeiras do passado, de outros modos de produção, que vivem na cidade, como a classe dos grandes proprietários rurais absenteístas, vivendo da renda da terra transferida para a cidade, e de grupos de imigrantes de origem rural não integrados plenamente à economia capitalista.

Mais importante, contudo, são as forças derivativas, oriundas da própria dinâmica do capitalismo, derivadas de suas necessidades intrínsecas, envolvendo, de um lado, o processo de acumulação e sua continuidade e, de outro, a reprodução de uma sociedade diferenciada. As forças derivativas tornaram mais complexa a sociedade capitalista, fragmentando-a em inúmeras classes e frações de classe. Geraram:

i - fragmentação da classe capitalista e do proletariado em razão da divisão do trabalho, do progresso técnico e da especialização funcional; em consequência, vários estratos sociais emergem, minimizando os efeitos das forças primárias;

ii - classes distintas de consumo, visando uma demanda variável e contínua, fundamental para a acumulação de capital;

iii - aparecimento de uma classe média, burocrática, trabalhando na esfera do Estado e de grandes empresas, com o objetivo de organizar e controlar a produção, a circulação, a distribuição e o consumo; acrescente-se que a classe média não é homogênea, apresentando diferenças quanto à renda, aos padrões culturais e a origem, a qual pode ser por ascensão social ou por decadência de parte de antigas elites; 
iv - desvio de consciência de classe e projeção ideológica da classe dominante, visando desviar a atenção dos problemas das relações capital-trabalho, explorando, por exemplo, os conflitos entre empregados e desempregados;

$\mathrm{v}$ - a necessidade de organizar as chances de mobilidade social que podem advir do processo de produção, circulação e distribuição e sua dinâmica, que podem criar instabilidade na estrutura social; é necessário, então, criar barreiras para controlar essa mobilidade, como se exemplifica com a educação diferenciada.

Harvey (1975) argumenta que essas forças são contraditórias, algumas levando a um antagonismo de configurações sociais, enquanto outras criam diferenciações favoráveis à reprodução da complexa sociedade capitalista. E na medida em que essas forças atuam intensamente e por longo tempo, geram uma marcante diferenciação social, ao mesmo tempo em que se verifica a crescente concentração espacial de população e atividades, isto é o desenvolvimento de grandes cidades, como se exemplifica com Chicago nos primeiros 30 anos do século XX.

A segregação residencial da cidade capitalista emerge, assim, a partir da localização diferenciada no espaço urbano das distintas classes sociais e suas frações. Admite-se que mais intensa a fragmentação social, mais complexa será a segregação residencial. Admite-se também que na identificação de classes sociais e suas frações devam ser consideradas combinações de um número de variáveis maior que aqueles sugeridos por Shevky e Bell (1974) e que já apareceram em diversos estudos empíricos.

Consideramos também que se torna necessário, nos estudos sobre áreas sociais, levar em conta que a segregação residencial é influenciada:

i - pelo tamanho da cidade, admitindo-se que o aumento do tamanho implique em maior heterogeneidade social;

ii - pelo tipo de cidade, ou seja, cidade comercial, cidade industrial, cidade administrativa e cidade que vive da renda da terra, entre outros tipos, pois para cada tipo verifica-se uma ação diferenciada das forças primárias, residuais e derivativas;

iii - o período histórico em que a cidade foi estudada, pois isto envolve significados distintos para cada uma das forças de estruturação social e consequentemente distintos modos de segregação residencial.

A segregação residencial e seus padrões espaciais, por outro lado, significam

i - de imediato o acesso diferenciado aos recursos da vida, sobretudo aqueles recursos escassos, que tendem a serem encontrados em áreas onde vive uma população de renda mais elevada e dotada de maior poder político para criar ou pressionar a criação de condições mais favoráveis de existência e reprodução. Harvey (1973) refere-se à renda real, isto é, a renda monetária que a população de alto status possui é ampliada em razão dos investimentos públicos e privados, criando aquelas condições mais favoráveis à vida;

ii - a existência de unidades espaciais, áreas sociais no nosso entender, favoráveis à interação social, a partir das quais, e dada a tendência à homogeneidade social de cada unidade espacial, os indivíduos elaboram valores, expectativas, hábitos e se preparam para ingressarem no mercado de trabalho; desenvolvem ainda um dado estado de consciência; nesse contexto 
de homogeneidade social, mais nítida nos extremos sociais e menos no âmbito da classe média, criam-se as condições de existência e reprodução diferenciadas, se se trata de áreas de relativa estabilidade social (Harvey, 1975); e

iii - a diferenciação espacial do processo de formação de classes sociais e suas frações (Harris, 1984; Katznelson, 1992) e de reprodução das relações sociais no âmbito da sociedade capitalista, como aponta Harvey (1975), a partir do pensamento de Lefébvre (1991).

Finalmente, é importante considerar os padrões espaciais da segregação residencial. Derivam eles de lógicas de localização e relocalização no espaço urbano das classes sociais e suas frações. Esses padrões são complexos e podem ser descritos por combinações de três possibilidades teóricas de segregação residencial propostos por Kohl-Sjoberg, Burgess e Hoyt (1958), como aponta Corrêa (1989a). Na primeira lógica, descrita por Kohl-Sjoberg, as elites localizam-se no centro e os pobres na periferia, sendo esse padrão associado à cidade pré-industrial. Na segunda, proposta por Burgess e já descrita por Engels 80 anos antes, as elites residem na periferia e os pobres na área central, especificamente na zona periférica do centro. Na terceira, finalmente, as classes sociais e suas frações estão localizadas não em círculos concêntricos a partir do núcleo central de negócios da cidade, como nas duas propostas anteriores, mas ao longo de setores a partir do núcleo central de negócios.

A combinação dessas possibilidades pode se tornar complexa, como ocorreu nas grandes cidades latino-americanas desde o século XVI ao final do século XX, como apontado por Yujnovsky (1971) e Bähr e Mertins (1983). A grande cidade latino-americana apresenta as três lógicas coexistindo no seu espaço urbano. $\bigcirc$ padrão complexo latino-americano evidencia permanências e mudanças de padrões espaciais pretéritos, envolvendo cristalização e invasão-sucessão descendente (filtering douwn) e tentativas do mesmo processo, porém ascendente (gentrification).

Admite-se, em realidade, que outros padrões de segregação residencial possam ser evidenciados. Devem ser interpretados como expressão de uma mais complexa realidade socioespacial e não como nenhuma forma de desvio. A inteligibilidade dessas combinações se dará à luz das lógicas possíveis de localização e relocalização das classes sociais e suas frações. Isto nos encaminha para as práticas espaciais associadas à segregação residencial.

\section{Práticas espaciais: segregação residencial e áreas sociais}

As áreas sociais, definidas pela segregação residencial, não são o produto da "mão invisível do mercado", nem de nenhuma outra entidade supraorgânica. Resultam de processos sociais e de práticas espaciais engendradas por agentes sociais concretos, com interesses, contradições e conflitos. Nessas práticas o Estado, particularmente na escala municipal, acha-se presente, seja diretamente, seja de modo indireto, participando de ações e negociações com outros agentes como os proprietários dos meios de produção, sobretudo as grandes empresas, os proprietários fundiários, os promotores imobiliários, os grupos sociais excluídos e inúmeros outros agentes sociais. A centralidade de cada um desses agentes, inclusive o Estado, é variável.

No presente texto considera-se aquelas práticas e seus agentes vinculados explicitamente à segregação residencial, sendo discutidos apenas dois tipos de práticas espaciais. 
As práticas espaciais aqui consideradas são entendidas, segundo Corrêa (1995, p. 35), como "um conjunto de ações espacialmente localizadas, que impactam diretamente sobre o espaço, alterando-o no todo ou em parte, ou preservando-o em suas formas e interações espaciais".

Definidas e integradas no contexto de cada sociedade, as práticas espaciais estão associadas às diferenças espaciais, de fundamental importância para a existência e reprodução de uma sociedade diferenciada. Nesse sentido, o conceito de práticas espaciais aqui adotado é lefebvriano em seus aspectos gerais (Lefébvre, 1991), mas neste autor o conceito tem um sentido mais amplo. Pretendemos especificá-lo mais, tornando-o mais restrito e mais operacional. Anteriormente definimos estas práticas como: seletividade espacial, fragmentação-remembramento espacial, antecipação espacial, marginalização espacial e reprodução da região produtora (Corrêa, 1992, 1995). Foi argumentado que estas práticas não eram mutuamente excludentes entre si.

Ao terem sido concebidas para o espaço regional, envolvendo a ação de uma grande corporação multifuncional e multilocalizada, torna-se necessário repensá-las em termos intraurbanos. Pois envolvem agentes sociais de natureza variada, com interesses, escalas espaciais de ação, tamanhos e atividades diferenciadas, atuando em um meio ambiente construído, denso e já profundamente heterogêneo, dotado ainda de dinâmica distinta daquela do espaço regional.

Torna-se necessário estabelecer a distinção entre práticas espaciais e processos espaciais. Segundo Corrêa (1979), processos espaciais são mediações por meio das quais os processos sociais originam formas, movimento e conteúdo sobre o espaço urbano. Constituem um conjunto de forças atuantes ao longo do tempo, gerando localizações, relocalizações e permanências das atividades e população sobre o espaço da cidade. Centralização, descentralização, coesão, segregação, invasão - sucessão e inércia caracterizam esses processos, que têm correspondência, no plano da descrição, mas não no da interpretação, com o conceito de processos ecológicos da Escola de Chicago. Os processos espaciais envolvem um longo período de tempo, diversos agentes sociais e amplos espaços. As práticas espaciais, ao contrário, dizem respeito a um curto período de tempo, um tipo particular de agente social e é, em muitos casos, espacialmente pontualizada. Um mesmo processo espacial pode conter diversas práticas espaciais; por outro lado, uma mesma prática espacial pode vincular-se a diversos processos espaciais.

À guisa de encaminhar a temática das práticas espaciais em termos de espaço urbano, apenas indicaremos dois tipos, submetendo-os à avaliação crítica.

i - Zoneamento - Prática que visa delimitar legalmente áreas, nas quais imposições e restrições são estabelecidas, com o objetivo de garantir ou criar atributos julgados relevantes ou mesmo necessários por aqueles que detêm poder para criar ou alterar a organização espacial. É o Estado, particularmente ao nível municipal, quem estabelece o zoneamento, cuja concepção e implantação é objeto de negociações entre grupos sociais distintos. $\bigcirc$ zoneamento envolve as atividades econômicas e o uso residencial, este sendo crucial na formação de áreas sociais. Os exemplos são numerosos. Citemos apenas as contribuições de Duncan e Duncan (1984; 2001), relativas aos subúrbios de alto status em New York, Westchester e Bedford, nos quais a prática de zoneamento tornou-os altamente seletivo, abrigando uma elite tradicional, que se recusa a misturar-se com a elite emergente e menos refinada. 
ii - Apropriação e valorização diferenciada da terra urbana. Esta prática manifesta-se de diferentes maneiras e gera áreas sociais profundamente distintas, de alto e de baixo status social. A pura e simples apropriação pelas elites das áreas por elas consideradas como de amenidades, constitui-se em exemplo corrente desta prática. A permissividade em torno de áreas consideradas sem amenidades e apropriadas pela população de baixo status social, constitui-se também em situação corrente. Indicaremos dois tipos de práticas associados:

- antecipação, na qual alguns investimentos pontuais de formas impregnadas de significados de status ou investimentos dispostos axialmente, como água, esgoto e vias de tráfego, estabelecem uma valorização diferenciada que se irradia pela área em torno. A implantação de um clube de golfe, de hipódromo ou de hotel de alto luxo ou infraestrutura sanitária, por exemplo, valorizam as áreas beneficiadas, elevando o preço da terra, que se torna assim uma reserva para a formação de áreas sociais de alto status. Esta prática tem gerado, em muitos casos, uma configuração espacial em setores, tal como descrito e analisado por Hoyt (1958) para a cidade norte-americana e por Yujnovsky (1971) e Bähr e Mertins (1983) para as cidades latino-americanas. Nesses setores formam-se áreas sociais de alto status;

- marginalização, que é a prática pela qual certos espaços são deixados de lado pelos investimentos públicos e privados, não sendo, portanto, valorizados, tanto em termos de valor de troca ou valor simbólico. Rejeitados pela população de alto status, esses espaços são ocupados por uma população de baixo status, originando áreas sociais correspondentes, caracterizadas pela favela, pelos cortiços ou por habitações produzidas pelo sistema de autoconstrução em loteamentos irregulares. Os conjuntos habitacionais, geradores de típicas áreas sociais, podem ser aí enquadrados em razão da localização dos mesmos, em áreas distantes dos setores seletivos.

Ações diversas poderão ser distinguidas, indicando a complexidade das práticas espaciais, das quais poucas foram aqui apontadas que, no entanto, deverão estar longe de esgotar o conjunto desse tipo de ação humana no âmbito de uma sociedade diferenciada e da qual o espaço social é reflexo e condição social.

\section{Áreas sociais e a cidade brasileira}

Processos sociais mais recentes, não considerados na teoria da increasing scale of society, envolvendo, entre outros aspectos, o aumento das tensões sociais, levaram a exacerbação de algumas formas de segregação residencial. Marcuse (1997), por exemplo, refere-se à proliferação e ressignificação dos enclaves, cidadelas e guetos nas cidades norte-americanas após 1970 , na cidade que se atribui a denominação cidade pós-fordista.

$\bigcirc$ enclave é reconceitualizado como uma área intraurbana caracterizada pela concentração de um grupo étnico minoritário, via de regra imigrante. Seus habitantes esforçam-se para participar mais efetivamente da sociedade na qual estão inseridos. Nesse sentido, o termo não deve ser confundido com o enclave imperial, a exemplo de um bairro britânico em uma cidade asiática, nem com a visão usual de uma área habitada por imigrantes. A cidadela é vista como uma área onde está concentrado um grupo de alto status, dotado de poder e riqueza e que, visando proteger ou reforçar a posição que detém isola-se das áreas em torno. Os condomínios fechados, protegidos com guaritas, e as ruas fechadas, com segurança própria, são 
exemplos de cidadelas. $\bigcirc$ gueto, finalmente, é redefinido como uma área onde concentra-se uma população de excluídos da sociedade e não de apenas dominados e explorados, que assim está inserido na sociedade de classe. Marcuse (1997), a propósito, refere-se ao "outcast ghetto", distinguindo-o de outras acepções, como a do gueto negro.

A formulação de Shevky e Bell (1974), por outro lado, ao focalizar a cidade norte-americana por volta de 1950, não aborda processos sociais e formas espaciais extremamente significativos para as cidades da América Latina e de outros contextos socioculturais. Trata-se de processo da "inchação" urbana, derivado da incapacidade da cidade em absorver parcela importante dos imigrantes e daqueles que nela nasceram. Trata-se, pode-se dizer, do "aumento da escala da pobreza", acompanhada do aumento da criminalidade. Esta não absorção de excedentes traduz-se no crescimento em número e tamanho de favelas, como pela "fragmentação do tecido sociopolítico-espacial" (Souza, 2000), com territórios controlados pelo narcotráfico e o escapismo das elites.

$\bigcirc$ que foi apresentado acima tem profundas implicações na dinâmica das áreas sociais da cidade brasileira e sugere a necessidade de se repensar criticamente a teoria das áreas sociais visando dar inteligibilidade ao espaço social da cidade brasileira na atualidade, para a qual merecem ser destacadas, em razão da abrangência e densidade de tratamento, as contribuições de Villaça (1998) e de Souza (2000).

Admite-se ainda que, a despeito dos problemas apontados por diversos autores sobre o setor censitário como unidade observacional problemática para a identificação de áreas sociais, esta é, contudo, a menor unidade de área disponível para uma pesquisa do tema em pauta. E isto é mais significativo quando se intenta realizar estudos comparativos para um certo número de cidades. A favor de sua adoção está o fato de se aceitar a tese de serem as áreas sociais uma construção intelectual e não uma entidade concreta, real, em relação a qual ao pesquisador compete reconhecê-las.

As áreas sociais a serem identificadas derivam de indicadores que, em sua maior parte, são os mesmos adotados por Shevky e Bell (1974) e McElrath (1962). Mas a interpretação dos resultados não se apoia na teoria do "aumento da escala da sociedade" e sim nos processos de industrialização e urbanização entendidos como geradores de mudanças na estrutura social, responsáveis pela reestruturação de classes sociais e por padrões locacionais específicos. Isto significa dizer que os mesmos indicadores podem ser interpretados a partir de bases teóricas distintas. Afinal, renda, instrução e ocupação, fundamentais na definição da dimensão status socioeconômico ou posição social, podem ser interpretados numa perspectiva positivista ou do materialismo histórico e dialético. A esse respeito, considera-se o estudo de Ribeiro e Lago (2000) que, fora do âmbito dos estudos de áreas sociais, abordam o espaço social de São Paulo, Rio de Janeiro e Belo Horizonte, com base, em grande parte, nos indicadores de renda, instrução e ocupação, definindo a posição social. 


\section{Indicações para se pensar a teoria das áreas sociais}

Ao se pensar sobre a teoria das áreas sociais incorpora-se as sugestões de McElrath (1962) a respeito das bases de diferenciação do espaço social da cidade, a industrialização e a urbanização. A primeira gera duas dimensões ou fatores, status socioeconômico ou posição social e status familiar, enquanto a segunda outras duas dimensões, status do migrante e status étnico. Admite-se, de acordo com Timms (1971), que os indicadores de cada uma dessas dimensões não são necessariamente independentes entre si. Admite-se ainda, com base em estudos empíricos realizados, que não há uma necessária sequência de um tipo mais primitivo para outro mais evoluído, quer dizer, a tese do "aumento da escala da sociedade" é vista como apenas uma possibilidade, já que mudanças na sociedade podem gerar diversas configurações sociais e espaciais.

Vejamos, então, as indicações relativas aos indicadores de cada uma das dimensões de diferenciação socioespacial.

i - status socioeconômico - Esta dimensão tem sempre emergido nos estudos realizados, apresentando um grande peso relativo entre as dimensões que emergem. Os indicadores que em princípio constituem esta dimensão são os mesmos apontados por Shevky e Bell (1974), ocupação, instrução e renda, acrescentando-se a natureza da habitação, em virtude do fato do acesso a ela ser problemático no contexto brasileiro. Nesse caso, entre as possíveis variáveis que comporão a natureza da habitação, aquelas que permitem identificar o seu caráter precário ou não, o número de cômodos, a infraestrutura disponível e o preço do imóvel ou do aluguel.

ii - status familiar - Os indicadores que usualmente compõem esta dimensão têm, em relação às cidades não ocidentais, apresentado uma associação com os indicadores de status socioeconômico. Esse é um ponto em aberto ao se considerar as cidades brasileiras. A fertilidade e o número de mulheres na força de trabalho são indicadores comuns em Shevky e Bell (1974) e em McElrath (1962). Acrescentaríamos, como outros o fizeram, variáveis associadas ao estágio do ciclo de vida e o número de mulheres como chefe de família, que pode revelar aspectos significativos sobre as áreas sociais das cidades brasileiras.

iii - status do migrante - Como sugerido por McElrath (1962) a origem do migrante constitui-se em indicador fundamental. Acrescentamos o tempo de permanência no local, capaz de indicar a atratividade antiga ou recente das diversas áreas da cidade.

iv - status étnico - É importante no caso brasileiro considerar a população negra, ainda que isto implique em dificuldades de definição.

Sugere-se, adicionalmente, que sejam considerados indicadores relativos à religião, focalizando particularmente no grupo religioso denominado evangélico, dada sua difusão na sociedade brasileira. Na interpretação das áreas sociais sugere-se que o espaço físico seja considerado, indicando-se os maciços, colinas, planícies, vales encaixados, lagoas, praias, áreas embrejadas etc., que desempenham papel crucial na configuração espacial das áreas sociais.

\section{A seleção de cidades}

Visando o conhecimento sistemático da ecologia fatorial da cidade brasileira sugere-se que na seleção de centros urbanos sejam considerados os seguintes critérios, tamanho, crescimento, funções, antiguidade e o espaço físico. Esses critérios devem possibilitar que uma rica tipologia de cidades segundo o conceito de áreas sociais possa ser identificada, evidenciando a diversidade do processo de configuração socioespacial das cidades brasileiras. 
$\bigcirc$ tamanho da cidade constitui-se em uma primeira distinção a ser feita, com base na tese de que maior a cidade em termos demográficos, maior a sua heterogeneidade social, resultante da ação mais intensiva das forças de estruturação social apontadas por Harvey (1975) ou de formação de classes sociais e suas frações, segundo argumentam Harris (1984) e Katznelson (1992). $\bigcirc$ tamanho da cidade interfere também nas atividades econômicas, afetando a sua estrutura ocupacional. A esse respeito a literatura geográfica evidencia a relação entre o aumento da população total da cidade e o aumento das atividades não básicas, isto é, voltadas para a própria população da cidade: a esse respeito consulte-se Corrêa (1989a) em sua breve discussão sobre classificação funcional de cidades.

Sugere-se que na seleção de cidades segundo o tamanho sejam consideradas as seguintes classes de tamanho: 20.000-49.999; 50.000-99.999; 100.000-249.999; 250.000-499.999; 500.000-999.999; e de um milhão e mais habitantes. São Paulo e Rio de Janeiro constituem situações específicas e devem ser consideradas, cada uma, como uma classe; a comparação entre elas é relevante e pode revelar aspectos cruciais para a questão. Sugere-se que sejam selecionadas, quando for o caso, áreas metropolitanas e aglomerações urbanas, entendidas como unidades funcionais, de efetiva formação de classes sociais e seu espraiamento.

As cidades com menos de 20.000 habitantes estão, em princípio, excluídas, porque apresentam uma diferenciação socioespacial menos complexa, especialmente à medida em que o tamanho demográfico diminui. É interessante, por outro lado, estabelecer comparações entre cidades de tamanhos distintos. Nesse caso, em vez da tese do "aumento da escala social", admite-se o possível efeito do "aumento da escala dimensional". Questiona-se assim, se as áreas sociais de cidades com 75.000, 250.000 e 800.000 habitantes, por exemplo, são influenciadas pelo tamanho demográfico.

$\bigcirc$ crescimento urbano, medido pelo aumento relativo da população urbana no último ou últimos períodos intercensitários, deve ser também considerado. Contudo, esse crescimento deve ser ponderado segundo as classes de tamanho das cidades, pois 20\% de aumento populacional tem efeitos diferentes em cidades de um milhão de habitantes e em cidades com 50.000 habitantes. A importância do crescimento na seleção de cidades incide no fato de que um grande crescimento em um curto período de tempo está, via de regra, associado às migrações, que têm o papel de alterar a composição das classes sociais, suscitar novas demandas habitacionais, criar novos espaços residenciais e, por meio do processo de invasão-sucessão, reconfigurar as antigas áreas sociais. A expansão de favelas, da autoconstrução e de conjuntos habitacionais que, em muitos casos expressam um crescimento demográfico acelerado, exemplificam os possíveis efeitos em termos de áreas sociais.

crescimento demográfico rápido é significativo quando são consideradas aquelas cidades que, com menos de 20.000 habitantes segundo o censo anterior, ultrapassam muito os 50.000 habitantes. Nesses casos, em cidades em área de fronteira de ocupação, os processos de formação de classes e de áreas sociais são simultâneos, revelando os meios pelos quais configura-se o espaço urbano.

A estrutura social do espaço urbano está intimamente associada às funções desempenhadas pela cidade. Regulam elas, em grande medida, o número de administradores de alto escalão, engenheiros, militares, grandes proprietários rurais absenteístas, operários, qualificados 
ou não, burocratas de nível médio, empregados no comércio etc. Também os desempregados e aqueles vinculados ao setor informal, em algum grau dependem das funções urbanas, por exemplo, das crises pelas quais elas passam. A ocupação, um índice fundamental na definição da situação socioeconômica, advém diretamente das funções urbanas, o mesmo se podendo dizer dos indicadores relativos à instrução e à renda. Os indicadores mulheres na força de trabalho e fertilidade, que compõem o fator situação familiar, também estão associados às funções urbanas. Os aposentados, por outro lado, devem também ser considerados em virtude da renda que aportam à cidade, especialmente às cidades de menor tamanho.

Sugere-se, então, que sejam consideradas cidades caracterizadas por diferentes combinações de funções, desde aquelas plenamente multifuncionais àquelas caracterizadas por poucas funções urbanas. Pensa-se em cidades fortemente industrializadas, cidades definidas como típicos lugares centrais, cidades dotadas da função de capital político-administrativa e cidades que, em grande parte, vivem da drenagem da renda fundiária.

Como aponta Firey (1974), a força de inércia das formas espaciais, muitas vezes pelo valor simbólico a elas atribuído, pode dar às cidades antigas um elemento diferenciador em relação àquelas que surgiram em um passado recente. A questão que se coloca é se a antiguidade, efetivamente, interfere na cristalização de áreas sociais criadas no passado. Ao contrário, pode se colocar ainda se em cidades novas certos processos locacionais, que originaram a denominada zona periférica do centro ou "zone in transition" de Burgess, estiveram ausentes, resultando em outra configuração socioespacial. Em um país como o Brasil é possível se pensar no papel da permanência de formas espaciais herdadas do passado, que desempenham um papel significativo na configuração espacial de suas cidades. À guisa de possíveis exemplos pensa-se em Salvador e Recife, de um lado, e Belo Horizonte e Goiânia, de outro, metrópoles regionais criadas em tempos distintos.

As cidades não estão situadas em planícies isotrópicas, homogêneas. Ao contrário, estendem-se sobre várias configurações geológico-geomorfológicas, apresentando e criando ainda microclimas distintos. Podem ainda ser cortadas por rios ou estarem à beira de um lago ou do mar. Os diferenciais que a natureza criou apresentam valores também diferenciados segundo os diversos contextos socioculturais. A apropriação da natureza, de um lado, é socialmente seletiva e, de modo geral, e em cada momento, os locais considerados como os melhores pelos grupos de alto status, são por eles apropriados. Esta apropriação, por outro lado, contribui para confirmar o status elevado daqueles que assim o fizeram.

Sugere-se que na seleção de cidades brasileiras leve-se em consideração as características diferenciadoras do espaço físico, pois estas interferem nos padrões espaciais das áreas sociais. Questiona-se sobre possíveis diferenças entre cidades litorâneas, com amenidades socialmente concebidas, e cidades do interior, sem praia. Questiona-se ainda sobre possíveis diferenças entre as cidades que se espraiam sobre monótonos chapadões e aquelas cujas topografias são marcadas por inúmeras colinas, cristas e maciços, ou localizadas ao longo de vales estreitos.

A partir desses critérios de seleção de cidades viabiliza-se a construção sistemática de uma tipologia de áreas sociais para as cidades brasileiras. À guisa de sugestão indica-se um conjunto de cidades de acordo com cada um dos cinco critérios acima indicados. Cada critério, isolado ou combinadamente, pode servir de base para a seleção de cidades. 
i - tamanho - Curitiba, Belém, Vitória, Campo Grande, Londrina, Uberlândia, Marilia, Passo Fundo e Mossoró;

ii - crescimento - cidades da fronteira de ocupação ou modernização, como Alta Floresta e Barreiras, e cidades com crescimento demográfico pequeno;

iii - função - Joinvile, Paranaguá, Feira de Santana, Alegrete e Aracaju;

iv - antiguidade - Salvador, São Luís, Goiânia, Bauru e Sinop;

v - espaço físico - Maringá, Petrópolis, Natal, Campos e Blumenau.

\section{Considerações finais}

Por um lado, este texto procurou resgatar os estudos sobre áreas sociais, demonstrando os antecedentes, as formulações iniciais e a operacionalização, exemplos selecionados, as críticas e generalizações e novas proposições e, finalmente, algumas perspectivas. De outro, também se insistiu na importância desse tema para compreender o espaço urbano como o lugar da existência e da reprodução da grande maioria da população.

Os seguintes pontos sumariam nossa interpretação sobre as áreas sociais:

i - A despeito de suas origens, calcadas em bases teóricas criticáveis e largamente abandonadas, as áreas sociais constituem, já em sua primeira versão, áreas naturais, o resultado da percepção desigual do espaço urbano, sendo merecedoras de atenção. Resgata-se o tema e não a interpretação original.

ii - É possível perceber, como Timms (1971) já concebera, uma diversidade de modelos que descrevam a variedade de configurações socioespaciais nas diferentes sociedades. Em vez de um modelo visto como universal, vários modelos particulares descrevem melhor a complexidade do mundo real. Por outro lado, essa variedade nos leva a ver na teoria do aumento da escala da sociedade apenas uma possibilidade. A proposição de McElrath (1962) é mais realista e não implica em uma visão teleológica.

iii - $\bigcirc$ Brasil constitui-se em um rico laboratório para estudos de áreas sociais, tendo sido propostos alguns pontos para realizar estudos sistemáticos sobre o tema em pauta, cuja importância ainda não foi nitidamente percebida por aqueles que estudam a sociedade em sua dimensão espacial e temporal.

\section{Referências}

ABU-LUGHOD, J. Testing the Theory of Social Area Analysis: The Ecology of Cairo, Egypt. American Sociological Review, v. 34, n. 2, p. 198-212, 1969.

ANDERSON, R.; EGELAND, J. Spatial Aspects of Social Area Analysis. In: SCHWIRIAN, K. P. Comparative Urban Structure. Lexington: D.C. Heath and Company, 1974.

BÄHR, J.; MERTINS, G. Un modelo de la diferenciación socio-espacial de las metrópolis de América Latina. Revista Geográfica, n. 98, p. 23-29, 1983.

BAILLY, A. S.; POLÈSE, M. Processus Urbains et Modelés Spatiaux: Ecologie Factorielle Comparée, Edmonton-Quebec. The Canadian Geographer, v. 21, n. 1, p. 59-80, 1977. 
BELL, W. Economic, Family and Ethnic Status: An Empirical Test. In: SCHWIRIAN, K. P. Comparative Urban Structure. Lexington: D.C. Heath and Company, 1974.

BERRY, B. J. L. Introduction: The Logic and Limitations of Comparative Factorial Ecology. Economic Geography, v. 47, n. 2, p. 209-219, 1971.

BROWETT, J. On the Necessity and Inevitability of Uneven Spatial Development Under Capitalism. International Journal of Urban and Regional Research, v. 8, n. 2, p. 155-175, 1984.

BULMER, M. The Chicago School of Sociology: Institutionalization, Diversity and the Rise of Sociological Research. Chicago: The University of Chicago, 1984.

CAPEL, H. Filosofia y ciencia en la Geografia Contemporánea. Barcelona: Barcanova, 1981.

CASTELLS, M. Problemas de investigación en sociología urbana. Buenos Aires: Siglo Veintiuno, 1971.

CORRÊA, R. L.; FREDRICH, O. B. L. As áreas sociais de San José, Costa Rica: apontamentos. Inédito

CORRÊA, R. L. O espaço: um conceito-chave da geografia. In: CASTRO, I. E; CORRÊA, R. L; GOMES, P. C. C. (Org.). Geografia: conceitos e temas. Rio de Janeiro: Bertrand Brasil, 1995.

. Corporação, práticas espaciais e gestão do território. Revista Brasileira de Geografia, Rio de Janeiro, v. 54, n. 3, p. 115-121, 1992. A rede urbana. São Paulo: Ática, 1989a. . O espaço urbano. São Paulo: Ática, 1989b.

Processos espaciais e a cidade. Revista Brasileira de Geografia, Rio de Janeiro, v. 41, n. 3, p. 100-110, 1979.

DUNCAN, J.; DUNCAN, N. Sense of Place as a Positional Good-Locating Bedford in Space and Time. In: ADAMS, P. C.; HOELSCHER, S.; TILL, K. E. Textures of Place: Exploring Humanistic Geographies. Minneapolis: University of Minnesota Press, 2001.

A Cultural Analysis of Urban Residential Landscape in North America: the case of Anglophile Elite. In: AGNEW, J.; MERCER, J.; SOPHER, D. The City in Cultural Context. Winchester: Allen \& Unwin, 1984.

ENGELS, F. A situação da classe trabalhadora na Inglaterra. Porto: Apontamentos, 1975.

ENTRIKIN, J. N. Robert Park's Human Ecology and Geography. Annals of the Association of American Geographers, v. 70, n. 1, p. 43-58, 1980.

FIREY, W. Sentimiento y simbolismo como variables ecológicas. In: THEODORSON, G. A. (Org.). Estudios de Ecología Humana. Barcelona: Labor, 1974. 
HARRIS, R. Residential Segregation and Class Formation in the Capitalist City: a Review and Directions for Research. Progress in Human Geography, v. 8, n. 1, p. 26-48, 1984.

HARVEY, D. Class Structure in a Capitalist Society and the Theory of Residential Differentiation. In: PEEL, R.; CHISHOLM, M.; HAGGETT, P. Processes in Physical and Human Geography. Londres: Heinemann, 1975.

Social Justice and the City. Londres: Edward Arnold, 1973.

HAWLEY, A. M.; DUNCAN, O. D. Social Area Analysis: A Critical Appraisal. Land Economics, v. 33, n. 4, p. 337-345, 1957.

HOYT, H. The Pattern of Movement of Residential Rental Neighborhood. In: MAYER, H. M.; KOHN, C. F. Readings in Urban Geography. Chicago: The University of Chicago Press, 1958.

JACKSON, P.; SMITH, S. Exploring Social Geography. Londres: Allen E Unwin, 1984.

JOHNSTON, R. J. Some Limitations of Factorial Ecology and Social Area Analysis. Economic Geography, v. 47, n. 2, p. 314-323, 1971.

KATZNELSON, I. Marxism and the City. Oxford: Clarendon, 1992.

LEFÉBVRE, H. The Production of Space. Oxford: Basil Blackwell, 1991.

Espacio y política. Barcelona: Península, 1976.

MARCUSE, P. The Enclave, the Citadel and the Ghetto. What Has Changed in the Post-Fordist U. S. City. Urban Affairs Review, v. 33, n. 2, p. 228-264, 1997.

MORRIS, F. B.; PYLE, G. F. The Social Environment of Rio de Janeiro in 1960. Economic Geography, v. 47, n. 2, p. 286-299, 1971. Supplement.

MURDIE, R. The Factorial Ecology of Metropolitan Toronto - 1951-1961: An Essay of the Social Geography of the City. University of Chicago, Department of Geography, Research Paper, 116, 1969.

PARK, R. E. A comunidade urbana como configuração espacial e ordem moral. In: PIERSON, D. (Org.). Estudos de ecologia humana. São Paulo: Martins, 1970.

Sugestões para a investigação do comportamento humano no meio urbano. In: VELHO, O. G. (Org.). O fenômeno urbano. Rio de Janeiro: Zahar, 1967.

REES, P. H. Factorial Ecology: An Extended Definition, Survey and Critique of the Field. Economic Geography, v. 47, n. 2, p. 220-233, 1971.

RIBEIRO, L. C.; LAGO, L. C. Q. ○ espaço social das grandes metrópoles brasileiras: São Paulo, Rio de Janeiro e Belo Horizonte. Revista Brasileira de Estudos Urbanos e Regionais, Recife, n. 3, p. 111-129, out. 2000.

SCHMID, C.; MACCANNELL, E.; VAN ARSDOL JR., M. Ecología de la ciudad americana: nuevas comparaciones y valorización de generalizaciones. In: THEODORSON, G. A. (Org.). Estudios de Ecología Humana. Barcelona: Labor, 1974. 
SHEVKY, E.; BELL, W. Análisis de área social. In: THEODORSON, G. A. (Org.). Estudios de Ecología Humana. Barcelona: Labor, 1974.

SHEVKY, E.; WILLIAMS, M. The Social Areas of Los Angeles: Analysis and Typology. Berkeley/Los Angeles: University of California, 1949.

SHORT, J. Social Systems and Spatial Patterns. Antipode, 8(1), p. 77-83, 1976.

SJOBERG, G. The Pre-Industrial City: Past and Present. New York: The Free Press, 1960.

SOUZA, M. L. O desafio metropolitano: um estudo sobre a problemática socioespacial nas metrópoles brasileiras. Rio de Janeiro: Bertrand Brasil, 2000.

SWEETSER, F. Factorial Ecology of Helsink, 1960. In: SCHWIRIAN, K. P. (Org.). Comparative Urban Structure. Lexington: D.C. Heath and Company, 1974.

TIMMS, D. W. The Urban Mosaic: Toward a Theory of Residential Differentiation. Cambridge: Cambridge University Press, 1971.

UDRY, J. R. Increasing Scale and Spatial Differentiation: New Tests of Two Theories from Shevky and Bell. Social Forces, v 42, n. 4, p. 403-413, 1964.

VAN ARSDOL JR.; M. CAMILLERI, S. F; SCHMID, C. F. La generalidad de los índices del área social urbana. In: THEODORSON, G. A. (Org.). Estudios de Ecología Humana. Barcelona: Labor, 1974.

VILLAÇA, F. O espaço intra-Urbano no Brasil. São Paulo: Studio Nobel, 1998.

WILLIAMS, R. Culture is Ordinary. In: GRAY, A.; MCGUIGAN, J. Studying Culture: An Introductory Reader. Londres: Arnold, 1997.

YUJNOVSKY, O. La estructura interna de la ciudad: el caso latinoamericano. Buenos Aires: Siap, 1971.

ZORBAUGH, H. W. Áreas naturais. In: PIERSON, D. (Org). Estudos de Ecologia Humana. São Paulo: Martins S.A., 1970. 